\title{
A CONCEPÇÃO EDUCATIVA DE TEMPO E ESPAÇO NA PERSPECTIVA DO MOVIMENTO DAS CIDADES EDUCADORAS
}

Valdeney Lima da Costa*

Flávia Russo Silva Paiva*

\section{Resumo}

O presente artigo analisa as categorias tempo e espaço na perspectiva do Movimento das Cidades Educadoras. Metodologicamente, realizamos uma pesquisa bibliográfica referenciada em pesquisadores que dialogam com a proposta educativa do referido movimento (MOLL, 2009; GADOTTI, 2009; GOMEZ-GRANELL; VILA, 2003) e, também, com outros autores que se debruçam sobre o estudo da ampliaçáo da jornada escolar e realizam reflexões acerca dos princípios das Cidades Educadoras (CAVALIERE, 2007, 2009; COELHO, 2014; SILVA, 2013). Realizamos ainda um estudo documental a partir das duas versóes da Carta das Cidades Educadoras (1990, 2004) e de documentos publicados pelo Ministério da Educação (MEC) sobre o Programa Mais Educação. Os resultados do presente ensaio revelam outra lógica de reorganização de tempos e espaços na perspectiva do Movimento das Cidades Educadoras.

Palavras-chave: Tempo escolar. Espaço. Cidades Educadoras.

\section{INTRODUÇÁO}

Este ensaio ${ }^{1}$ resultou de nossas discussões no âmbito do grupo de pesquisa do qual participamos - NEEPHI ${ }^{2}$, grupo este que investiga, desde 1995, temas relacionados à ampliaçáo do tempo e dos espaços escolares, concepções, políticas e práticas de educação integral ${ }^{3}$ na escola pública brasileira e sobre as políticas públicas de jornada escolar ampliada.

Considerando que tempo e espaço constituem-se em elementos essenciais de uma proposta de ampliação da jornada escolar, o presente artigo analisa essas categorias na perspectiva do Movimento das Cidades Educadoras, surgido na cidade espanhola de Barcelona, no ano de 1990. Este movimento, cujas ideias foram expressas em declaraçóes publicadas nos anos de 1990 e 2004, tem sido o referencial teórico de algumas políticas governamentais de educação integral e (ou) tempo integral no Brasil, a exemplo do Programa Mais Educação ${ }^{4}$ em nível nacional.

$\mathrm{Na}$ perspectiva da elaboração do presente texto, metodologicamente, realizamos uma pesquisa bibliográfica referenciada em pesquisadores que dialogam com a proposta educativa do referido movimento, dos quais

Professor Assistente da Universidade Estadual do Piauí (UESPI). Doutorando em Educação pelo Programa de Pós-graduação em Educação (PPGEdu) da Universidade Federal do Estado do Rio de Janeiro (UNIRIO). Pesquisador do Núcleo de Estudos Tempos, Espaços e Educação Integral (NEEPHI)/UNIRIO. E-mail: pedagogo.ney@gmail.com

Doutoranda em Educação pelo Programa de Pós-graduaçáo em Educação (PPGEdu) da Universidade Federal do Estado do Rio de Janeiro (UNIRIO). Pesquisadora do Núcleo de Estudos Tempos, Espaços e Educação Integral (NEEPHI)/UNIRIO. E-mail: flavia.rspaiva@gmail.com

Instrumento: R. Est. Pesq. Educ., Juiz de Fora, v. 19, n. 2, jul./dez. 2017 
destacamos Moll (2009), Gadotti (2009) e GomezGranell e Vila (2003), e também com outros autores que se debruçam sobre o estudo da ampliação da jornada escolar e realizam reflexóes acerca dos princípios das Cidades Educadoras, a saber: Cavaliere (2007, 2009), Coelho (2014), Silva (2014), dentre outros. Além dessa pesquisa de caráter bibliográfico, realizamos um estudo documental a partir das duas versóes da Carta das Cidades Educadoras (1990, 2004) e de documentos publicados pelo Ministério da Educação (MEC) sobre o Programa Mais Educação.

$\mathrm{O}$ artigo foi organizado em quatro seçōes (além da introdução): (1) inicialmente, abordamos o tempo e o espaço como categorias de estudo no campo educacional. Neste exercício, compreendemos que a discussão sobre o tema da ampliação da jornada escolar, necessariamente, remete-nos às reflexôes sobre as relações entre o tempo, o espaço e a escola. Sendo assim, o estudo dessas categorias é relevante para compreendermos outras questôes que permeiam não somente a organização escolar, mas também o próprio processo educacional em sentido amplo; (2) na segunda seção, inferimos sobre as concepções de tempo e espaço nos pressupostos do Movimento das Cidades Educadoras. Neste ensejo, trazemos para nossa reflexão os fundamentos desse movimento expressos em duas cartas elaboradas e divulgadas mundialmente; (3) a terceira parte do artigo aborda como as ideias do movimento supracitado estão presentes em documentos educacionais, produzidos por especialistas do Ministério da Educação (MEC), que apresentam o Programa Mais Educação; (4) para concluir, na última seção apresentamos nossas consideraçóes sobre o tema em questáo, socializando algumas de nossas reflexóes para o debate.

Continuamos com o texto, questionando: quais contribuições o estudo sobre tempo e espaço fornece à problemática da ampliação da jornada escolar (brasileira)?

\section{TEMPO E ESPAÇO COMO CATEgorias DE ESTUDO}

Neste item, buscamos tecer algumas reflexóes em relação ao tempo e ao espaço definindo-os com base em alguns estudiosos e abordando como esses elementos encontram-se referenciados em algumas legislações educacionais brasileiras.

Tempo e espaço consistem em elementos intrinsecamente associados, tendo em vista que "toda atividade humana precisa de um espaço e um tempo determinados" (CORREIA, 1996, p. 7) para se realizar. Essa associação se mantém quando abordamos tais categorias enquanto instrumentos político-pedagógicos em propostas de ampliação da jornada escolar.

Especificamente em relação ao tempo, Elias (1998) caracteriza-o como uma construção humana e um símbolo social, pois este foi criado pelos indivíduos e é largamente utilizado a partir de instrumentos como o relógio, o cronômetro, dentre outros, enquanto ferramenta que possibilita a medição do tempo. Coadunando com o entendimento de Elias (1998), Parente (2010, p. 137) reforça que a categoria tempo consiste em um "conceito histórico, social e cultural", o que implica que este "não é elemento a priori, ou seja, que existe assim como os diversos elementos da natureza”. Desse modo, o tempo é uma criação humana e, por isso, tem passado por diversas transformaçóes no decorrer da história. Tal fato possibilita-nos relacioná-lo com os tempos escolares, bem como a outros associados a ele, pois também consistem em tempos que passaram e passam por várias modificações.

Nesse sentido, Parente (2006, 2010) aborda a abrangência da noção dos tempos escolares, caracterizando-os como tempos de escola, tempos de escolarização e tempos na escola, de modo que, nesta última classificação, conforme veremos adiante, incluise o tempo integral escolar. 
Segundo a autora supracitada, o termo tempos de escola refere-se ao início e ao tempo de duração da escolarização, ou seja, está associado à definição de uma idade específica para o indivíduo se matricular na escola e de um período em que este deve permanecer nesta instituição. No contexto educacional brasileiro, por exemplo, a Lei $n^{\circ} 11.274 / 2006$ estabelece que o Ensino Fundamental obrigatório tenha duração de nove anos e a Emenda Constitucional no 59/2009 altera o inciso I do art. 208 da Constituição Federal de 1988, regulamentando que a idade mínima para efetuar matrícula em escolas regulares passa a ser quatro anos de idade, sendo que as legislaçóes anteriores determinavam idades e períodos diferentes. No que tange à dimensão do tempo escolar intitulada tempos de escolarização, Parente (2010) a compreende como as formas de organizar a educação escolar, seja em séries, ciclos, dentre outras. No âmbito da educação escolar brasileira, a forma predominante consiste no modelo seriado, organizando o tempo de escolarização em séries anuais. E, por fim, tempos na escola é uma noção de tempo escolar que se volta para as construçóes consolidadas no interior das instituições escolares - os novos tempos que são criados pela própria escola, compreendendo, principalmente, "as formas de organização do trabalho pedagógico na escola e as iniciativas de educação em tempo integral" (PARENTE, 2006, p. 23).

No presente estudo, como privilegiamos a discussão sobre a noção tempos na escola (PARENTE, 2006, 2010) e, mais especificamente, a questão do tempo no contexto das experiências educacionais de ampliação da jornada escolar, faz-se necessário apresentarmos as definiçôes, em termos legais, de tempo integral e jornada ampliada, pois, embora frequentemente utilizadas como sinônimas, tais expressóes possuem significados diferenciados na legislação educacional.

A terminologia tempo integral foi primeiramente referenciada pela Lei de Diretrizes e Bases da Educaçáo
Nacional (LDBEN), Lei no 9.394, de 20 de dezembro de 1996 , mais especificamente no artigo 34 , em seu $\$$ $2^{\circ}$ e, ainda, no $\$ 5^{\circ}$ do artigo 87. $\mathrm{O}$ art. 34 da referida legislação educacional estabelece que "a jornada escolar no Ensino Fundamental incluirá pelo menos quatro horas de trabalho efetivo em sala de aula, sendo progressivamente ampliado o período de permanência na escola” e, em seu $₫ 2^{\circ}$, menciona a expressão tempo integral sugerindo que o Ensino Fundamental seja "ministrado progressivamente em tempo integral, a critério dos sistemas de ensino”. Além disso, no $\$ 5^{\circ}$ do art. 87, a LDBEN/1996 recomenda a conjugação de esforços para a progressão das redes escolares urbanas de Ensino Fundamental para o regime de escolas de tempo integral.

Sendo assim, podemos observar que, embora a Lei no 9.394/1996, que estabelece as diretrizes e bases da educação nacional, tenha mencionado a expressão tempo integral, tal aparato legal não a definiu. Uma primeira definição do que seja esse tempo escolar caracterizado por integral só foi expressamente indicada pela Lei no 10.172, de 09 de janeiro de 2001, a qual aprovou o Plano Nacional de Educação (PNE, 20012010), em seu artigo 21, precisamente em sua meta 21 , que recomenda "ampliar, progressivamente a jornada escolar visando expandir a escola de tempo integral, que abranja um periodo de pelo menos sete horas diárias, com previsão de professores e funcionários em número suficiente" (BRASIL, 2001, grifos nossos).

Diante disso, a partir do artigo 21 da Lei $\mathrm{n}^{\mathrm{o}} 10.172 / 2001$, podemos compreender que tempo integral se refere a um período de, no mínimo, sete horas diárias de trabalho escolar. E essa interpretaçáo foi confirmada quando, posteriormente, na ocasião da publicação do Decreto no 6.253 , de 13 de novembro de 2007, o qual dispóe sobre o Fundo de Manutenção e Desenvolvimento da Educação Básica e de Valorização dos Profissionais da Educação (FUNDEB), foi descrito 
no art. $4^{\circ}$ que "considera-se educação básica em tempo integral a jornada escolar com duração igual ou superior a sete horas diárias, durante todo o período letivo, compreendendo o tempo total que um mesmo aluno permanece na escola ou em atividades escolares".

Vale destacarmos que, a partir desse dispositivo legal, também foi possível inferir o que seja jornada ampliada, tendo em vista que esta expressão não havia sido definida expressamente por nenhuma legislação, distinguindo-a de tempo integral. Assim, por jornada ampliada podemos considerar, mediante interpretação das legislaçóes em comento, um tempo escolar maior que o regular - de quatro horas diárias. Portanto, em termos quantitativos, concluímos que "tempo integral" é um tipo de "jornada ampliada”.

Associada ao debate sobre o tempo, a questão espacial também tem se constituído como categoria de estudo por pesquisadores concebendo-a como elemento importante para os processos educacionais.

Quanto ao elemento espaço, este é "formado por um conjunto indissociável, solidário e também contraditório, de sistemas de objetos e sistemas de ações, não considerados isoladamente, mas como o quadro único no qual a história se dá" (SANTOS, 1996, p. 51). Em termos conceituais, a palavra "espaço" deriva da geografia e representa dimensôes físicas e estruturais. Fundamentando-nos em Santos (1996), interpretamos que todo e qualquer espaço se constitui enquanto instrumentos e signos que comunicam invisivelmente ideologias e regras que organizam o(s) tempo(s) e o ambiente social. Logo, o elemento espaço não pode ser entendido apenas por suas características geográficas, faz-se necessário considerar também suas dimensões sociais, já que estas contribuem para significações culturais, estéticas, cognitivas, políticas, econômicas e afetivas.

O entendimento de Santos (1996) vai ao encontro do que expóe Frago (1998, p. 63) quando este considera que "o conhecimento de si mesmo, a história interior, a memória, em suma, é um depósito de imagens. De imagens de espaços que, para nós, foram, alguma vez e durante algum tempo, lugares”. Diante disso, o espaço provoca simbolicamente influências naqueles que o habitam ou habitaram e, por isso, é um elemento que contribui para a formação humana.

As reflexóes acima apresentadas quanto ao elemento espaço despertam-nos inquietaçóes sobre o espaço escolar e sobre os diferentes lugares destinados para a realização da prática pedagógica, principalmente em relação aos espaços em que ocorrem atividades educacionais no contexto de desenvolvimento de experiências de ampliação da jornada escolar. Pois, conforme afirma Frago (1998, p. 75), o espaço consiste em um "[...] mediador cultural em relação à gênese e formação dos primeiros esquemas cognitivos e motores, ou seja, um elemento significativo do currículo, uma fonte de experiência e aprendizagem" (ESCOLANO, 1998, p. 26).

Direcionando nosso olhar para os espaços destinados à realização de atividades da jornada escolar ampliada, a LDBEN/1996 indica que a educação escolar deve ser desenvolvida em instituições próprias para esse fim, conforme é possível evidenciar no art. $1^{\circ}$, o qual expõe que "esta Lei disciplina a educação escolar, que se desenvolve, predominantemente, por meio do ensino, em instituições próprias" (BRASIL, $\$ 1^{\circ}$, art. $1^{\circ}$, Lei $\left.{ }^{\circ} .9 .394 / 96\right)$. Isso confere ao espaço escolar uma significativa responsabilidade para com a educação dos sujeitos. A gratuidade do ensino público em estabelecimentos oficiais reforça essa inferência. Diante disso, podemos considerar que o espaço escolar é o local responsável pelo desenvolvimento da educação formal escolar.

A legislação mais recente que trata da jornada ampliada e que, em certa medida, propóe deliberadamente a utilização de espaços para além 
dos muros da escola é a Lei 13.005/2014, que aprovou o Plano Nacional de Educação 2014-2024. Nesse sentido, a meta 6 do referido plano propóe "oferecer educação em tempo integral em, no mínimo, 50\% (cinquenta por cento) das escolas públicas, de forma a atender, pelo menos, $25 \%$ (vinte e cinco por cento) dos(as) alunos(as) da educação básica" (BRASIL, Lei n ${ }^{\circ}$ 13.005/2014). Uma das estratégias para a consecução desse objetivo recomenda "fomentar a articulação da escola com os diferentes espaços educativos, culturais e esportivos e com equipamentos públicos, como centros comunitários, bibliotecas, praças, parques, museus, teatros, cinemas e planetários" (idem).

Dando continuidade ao presente ensaio, passamos à seção seguinte, ocasiáo em que abordamos as categorias tempo e espaço na perspectiva engendrada pelo Movimento das Cidades Educadoras.

\section{Tempo e espaço na perspectiva do Movimento das Cidades Educadoras}

Dados os limites deste texto, bem como o propósito, definido na parte introdutória deste artigo, não nos propomos a descrever exaustivamente $\mathrm{o}$ conceito de Cidade Educadora ${ }^{5}$, optando por trazer à tona, no presente texto, as implicaçóes dessa perspectiva no debate atual da ampliação da jornada escolar na educação brasileira.

O movimento em questão teve origem no ano de 1990, quando um conjunto de cidades reunidas em Barcelona, na Espanha, adotaram a ideia de pensar a educação da cidade, reconhecendo-a como espaço educativo e formativo de seus residentes. Assim, partiuse da premissa de que diferentes lugares citadinos dispunham de possibilidades educativas que deveriam ser reconhecidas por seus moradores.

A cidade será educadora quando reconheça, exerça e desenvolva, para além das suas funçóes tradicionais (econômica, social, política e de prestaçáo de serviços), uma função educadora, isto é, quando assuma uma intencionalidade e responsabilidade, cujo objetivo seja a formaçáo, promoção e desenvolvimento de todos os seus habitantes, a começar pelas crianças e pelos jovens (CARTA DAS CIDADES EDUCADORAS, 1990, p. 01).

Reunidas, portanto, na cidade espanhola, diferentes representantes de vários países assinaram a primeira versão da Carta das Cidades Educadoras, posteriormente revisada e relançada no ano de 2004 . O Brasil também passou a ser signatário desse movimento, de modo que alguns municípios se integraram à Associação Internacional das Cidades Educadoras, a exemplo de Nova Iguaçu - RJ e Belo Horizonte - MG, consideradas pioneiras no país na difusão dos princípios educacionais que norteiam o projeto educativo de cidade.

Em suma, a proposta educacional referenciada no movimento citado compreende a amplitude da educação, por um lado, e, por outro, o caráter educativo que as cidades podem assumir, independentemente de sua dimensão territorial. Nesse sentido, seus signatários defendem a ressignificação dos tempos, dos espaços e do papel social das instituiçôes (inclusa a escola) visando à formação integral dos indivíduos.

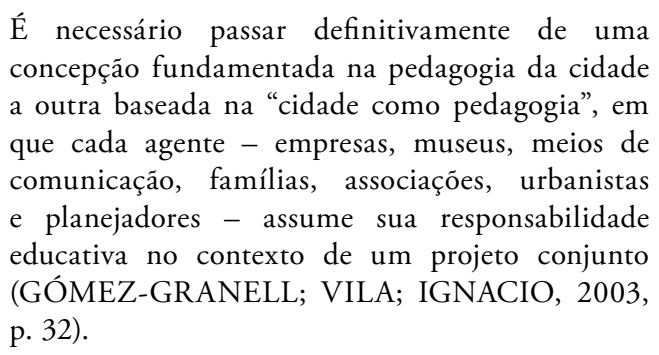

De acordo com esse entendimento, a responsabilidade educacional pressupóe tarefa de todos, náo apenas dos governantes da cidade. Ademais, essa perspectiva considera que não é apenas a escola que educa, mas outros espaços espalhados pelo território da cidade, tais como museus, teatros, praças, parques, dentre 
outros. Dessa forma, "quando a escola compartilha a sua responsabilidade pela educação, ela não perde seu papel de protagonista, porque sua ação é necessária e insubstituível, porém não é suficiente para dar conta da tarefa da Educação Integral” (MOLL, 2007, p. 32).

$\mathrm{Na}$ realidade brasileira, os princípios da Cidade Educadora estâo materializados nos documentos governamentais produzidos sobre o Programa Mais Educação, conforme apontaram os estudos de Cavaliere (2007, 2009) e Silva (2013). Diante disso, indagamonos sobre quais as implicações desses princípios nas diretrizes do PME, discussão presente no item que se segue.

\section{Concepçáo educativa das Cidades EdUCADORAS E SUAS IMPLICAÇÓES nas diretrizes do Programa Mais EducaÇÃo}

O Programa Mais Educação, de iniciativa do governo federal, foi instituído pela Portaria Interministerial $\mathrm{n}^{\circ} 17$, de 24 de abril de 2007, e pelo Decreto $n^{\circ} 7.083$, de 27 de janeiro de 2010, integrando as ações do Plano de Desenvolvimento da Educação, e vem induzindo experiências de ampliação da jornada escolar no país, cumprindo, assim, sua finalidade principal. As diretrizes desse programa enfatizavam a educação integral na perspectiva do movimento das Cidades Educadoras e defendem uma educação que busque superar o processo de escolarização centrado na figura da escola, afirmando ser ela, de fato, o lugar da aprendizagem dos saberes curriculares e oficiais na sociedade; todavia, alertam que a escola não deve ser considerada como a "única instância educativa" (BRASIL, 2009, p. 5).

Vale destacar o texto da Portaria Interministerial no $17 / 2007$, precisamente o parágrafo único do art. $1^{\circ}$, quando este indica que "o programa será implementado por meio do apoio à realização, em escolas e outros espaços socioculturais, de ações socioeducativas no contraturno escolar [...]" (BRASIL, Portaria Interministerial $n^{\circ}$ 17/2007).

Diante desse excerto, podemos perceber que a normatização do Mais Educação defende a realização de atividades na escola e para além dos espaços dessa instituição no contraturno escolar, ou seja, defende uma ampliação da jornada do aluno no espaço da escola e fora dele. A nosso ver, essa é uma nova concepção de jornada ampliada, a qual propóe um aumento do tempo e dos espaços dos alunos sob a responsabilidade da escola, mas não se realizando necessariamente em suas dependências internas.

Para reforçar esse entendimento, observamos ainda os princípios desse programa expostos no art. $2^{\circ} \mathrm{do}$ Decreto no 7.083/2010. Um deles se refere à "constituição de territórios educativos para o desenvolvimento de atividades de educação integral, por meio da integração dos espaços escolares com equipamentos públicos como centros comunitários, bibliotecas públicas, praças, parques, museus e cinemas" (BRASIL, Inciso II, art. 2, Decreto no 7.083/2010). Já outro princípio, também destacado no mesmo dispositivo jurídico, recomenda, com o Programa Mais Educação

[...] o incentivo à criação de espaços educadores sustentáveis com a readequação dos prédios escolares, incluindo a acessibilidade, e à gestão, à formação de professores e à inserção das temáticas de sustentabilidade ambiental nos currículos e no desenvolvimento de materiais didáticos (Inciso II, art. $2^{\circ}$, Decreto no $7083 / 2010$ ).

Observando esses e outros princípios que norteiam o referido programa, inferimos que a utilização de termos como territórios educativos, integração dos espaços escolares com equipamentos públicos, espaços educadores sustentáveis e sustentabilidade ambiental aludem à perspectiva do projeto educativo das Cidades Educadoras. Em nossa compreensão, essas ideias são 
acrescidas de outros conceitos (intersetorialidade, agentes educativos, parcerias, proteção social de crianças e adolescentes em situação de pobreza e vulnerabilidades) que fundamentam atualmente a política federal de jornada ampliada, constatação essa também percebida em relação à meta 6 do PNE 2014/2024, precisamente nas estratégias $6.1 ; 6.2 ; 6.4$ e 6.5 .

A concepção educacional de Cidade Educadora também repercutiu no debate sobre a mpliação da jornada escolar. De que forma? Em primeiro lugar, valorizando os tempos e espaços não escolares, que poderiam assumir caráter educativo. De outra, defendendo a articulação da escola com esses espaços. O que isso representou? Ora, deu surgimento a diferentes "modelos" organizacionais de ampliação da jornada, a maioria deslocando o tempo vivido de alunos da escola para dependências espaciais externas a esta, como igrejas, museus, praças, centros comunitários, dentre outros.

Como nos diz Cavaliere (2007), muitos dos projetos governamentais de escola de tempo integral surgiram, sobretudo a partir de 2003, com a ideia de que as atividades da jornada ampliada não precisam, necessariamente, ser desenvolvidas no próprio espaço escolar onde o aluno estuda, sendo necessária a articulação dessa instituição com outras situadas no bairro ou mesmo na cidade. Nessa perspectiva, inseriuse, conforme exposto, o Programa Mais Educação.

Ao estudar sobre as diferentes formas como se realiza a ampliação do tempo escolar no Brasil, Cavaliere (2007) apresenta, para fins didáticos, dois possíveis formatos organizacionais pelos quais se configuram as propostas de ampliação do tempo escolar no país, sendo estes denominados "escola de tempo integral" e "alunos em tempo integral". O primeiro formato aposta para o fortalecimento da instituição escolar, e para isso sugere "mudanças em seu interior pela atribuição de novas tarefas, mais equipamentos e profissionais com formação diversificada, pretendendo propiciar a alunos e professores uma vivência institucional de outra ordem" (CAVALIERE, 2009, p. 53). Já o formato esquemático "alunos em tempo integral" enfatiza a oferta de atividades escolares diversificadas aos educandos no turno oposto ao período das aulas do ensino regular, ou seja, no contraturno, a partir da "articulação com instituições multissetorias, utilizando espaços e agentes que não são os da própria escola, pretendendo propiciar experiências múltiplas e não padronizadas" (CAVALIERE, 2009, p. 53).

\section{Algumas consideraçóes}

Consideramos que a discussão sobre as relações entre tempo, espaço e a escola é relevante para compreendermos outras questóes que permeiam não somente a organização escolar, mas também o próprio processo educacional em sentido amplo.

A partir da discussão desenvolvida neste artigo, concluímos que conceitos como tempo e espaço vêm sendo ressignificados ao longo dos últimos anos na legislação brasileira. Acreditamos que a reestruturação do capital, bem como o avanço tecnológico, exigiu mudanças na sociedade e isso corroborou para novas perspectivas de organizaçáo do(s) tempo(s) e do(s) espaço(s) da escola. Essas transformações, conforme vimos, refletiram, em certa medida, no ordenamento jurídico educacional brasileiro.

Este estudo revelou a emergência de outra lógica de reorganização de tempos e espaços na perspectiva do Movimento das Cidades Educadoras. No que tange à jornada ampliada, preconiza-se essa ampliação, preferencialmente, em outros espaços considerados educativos, para além da instituição escolar, orientação expressa em documentos norteadores do Programa Mais Educação.

Observamos também que, nos últimos anos, os projetos e programas governamentais que propóem a educação em tempo integral têm se configurado com 
base no formato organizacional "alunos em tempo integral" e também se fundamentando nas orientações do movimento das Cidades Educadoras, principalmente no tocante à utilização de espaços para além do ambiente físico da escola (PAIVA et al., 2014), ou seja, partindo do princípio de que a educaçấo em tempo integral pode ser ofertada a partir da realização de atividades em outros espaços, mediante a consolidação de parcerias com entidades não governamentais ou com instituiçóes da sociedade civil organizada, a exemplo do CENPEC, Cidade Escola Aprendiz e Instituto Paulo Freire (SILVA, 2013). Trata-se de um debate caloroso, que merece, portanto, ser discutido em outras ocasióes.

\section{The EDUCATIONAL CONCEPTION OF TIME AND SPACE IN THE PERSPECTIVE OF THE movement of Educating Cities}

\section{Abstract}

This article analyzes the categories time and space from the perspective of the Movement of Educating Cities. Methodologically, we carried out a bibliographical research referenced in researchers that dialogue with the educational proposal of this movement (Moll, 2009; Gadotti, 2009; Gomez-Granell \& Vila, 2003) and also with other authors who study the study of the magnification Of the school day and reflect on the principles of Educating Cities (Cavaliere, 2007, 2009, Coelho, 2014 and Silva, 2013). We also conducted a documentary study based on the two versions of the Charter of Educating Cities (1990, 2004) and documents published by the Ministry of Education (MEC) on the More Education Program. The results of this essay reveal another logic of reorganization of times and spaces from the perspective of the Educating Cities Movement.
Keywords: School time. Space. Educating Cities.

EL CONCEPTO DE FORMACIÓN DE TIEMPO Y ESPACIO EN LA PERSPECTIVA del Movimiento DE Ciudades EDUCADORAS

\section{Resumen}

Este artículo analiza las categorías de tiempo y espacio en la perspectiva Movimiento de Ciudades Educadoras. Metodológicamente, se realizó una literatura mencionada en los investigadores que el diálogo con la propuesta educativa de ese movimiento (Moll, 2009; Gadotti, 2009; GómezGranell y Vila, 2003) y también con otros autores que se centran en el estudio de la expansión el día escolar y darse cuenta de las reflexiones sobre los principios de Ciudades Educadoras (Cavaliere, 2007, 2009; Coelho, 2014; Silva, 2013). También se realizó un estudio documental de las dos versiones de la Carta de Ciudades Educadoras $(1990,2004)$ y los documentos publicados por el Ministerio de Educación (MEC) en el Programa Más Educación. Los resultados de este ensayo muestran otra reorganización tiempo y espacios lógicos en la perspectiva Movimiento de Ciudades Educadoras.

Palabras clave: Tiempo de la escuela. El espacio. Ciudades Educadoras.

\section{Notas}

Trabalho apresentado no Colóquio Luso-brasileiro de Currículo, realizado em 2016, na cidade de Recife - PE. Revisado e ampliado para fins desta publicação.

Núcleo de Estudos Tempos, Espaços e Educação Integral, criado em 1995, vinculado ao Programa de Pós-graduação em Educação (PPGEdu) da Universidade Federal do Estado do Rio de Janeiro (UNIRIO).

Entendemos por educação integral o "trabalho educativo que entretece as várias possibilidades de conhecimento e saberes que consolidam sócio-historicamente falando, a formação humana” 
(COELHO, 2009, p. 186). Trata-se de uma concepçáo dentre outras existentes sobre a temática.

Este programa foi reformulado e renomeado no governo presidencial de Michel Temer (PMDB), denominando-se por Programa Novo Mais Educaçáo (PNME), instituído pela Portaria ministerial $\mathrm{n}^{\circ} 1.144 / 2016$, cuja finalidade é a melhoria da aprendizagem em Língua Portuguesa e Matemática dos alunos participantes do programa. Nesse sentido, as inferências apresentadas neste texto reportam-se à concepção do programa anteriormente vigente.

Para tal fim, ver Vintró (2003), Serra e Rios (2015) ou acessar diretamente a Carta das Cidades Educadoras, disponível em: <http://comunidadesdeaprendizagem.org.br/ Cartadascidadeseducadoras.pdf >. Acesso em 23 jun. 2016.

\section{REFERÊNCIAS}

BRASIL. Decreto no 6.523, de 13 de novembro de 2007. Dispóe sobre o Fundo de Manutençáo e Desenvolvimento da Educação Básica e de Valorizaçáo dos Profissionais da Educação (FUNDEB), regulamenta a Lei 11.494, de 20 de junho de 2007. Diário Oficial da União, Brasília, DF, 26 abr. 2007.

. Decreto no 7.083, de 27 de janeiro de 2010. Dispóe sobre o Programa Mais Educaçáo. Diário Oficial da União, Brasília, DF, 27 jan. 2010.

. MEC. Portaria Normativa Interministerial $n^{\circ} 17$, de 24 de abril de 2007. Institui o Programa Mais Educação. Diário Oficial da União, Brasília, DF, 26 abr. 2007.

MEC. Programa Mais Educação: Manual passo a passo. Brasília, DF, 2009.

\section{CARTA DAS CIDADES EDUCADORAS.} Proposta definitiva. 2004. Disponível em <http://comunidadesdeaprendizagem.org.br/ Cartadascidadeseducadoras.pdf>. Acesso em 19 abr. 2016.

CARTA DAS CIDADES EDUCADORAS. Declaração de Barcelona. 1990. Disponível em <https://5cidade.files. wordpress.com/2008/04/cartacidadeseducadoras.pdf> Acesso em 19 de abr. 2016.

CAVALIERE, A. M. V. Escolas de tempo integral versus alunos em tempo integral. Em Aberto, Brasília, v. 22, n. 80, p. 51-63, abr. 2009.

Tempo de escola e qualidade na educação pública Educucação e Sociedade, Campinas, vol. 28, n. 100 - Especial, p. 1.015-1.035, out. 2007.
COELHO, L. M. C. C. História(s) da educação integral. Em Aberto, Brasília, v. 22, n. 80, p. 83-96, abr. 2009.

Integração escola-território: "saúde" ou "doença" das instituiçôes escolares? In: MAURÍCIO, L. V. (Org.) Tempos e espaços escolares: experiências, políticas e debates no Brasil e no Mundo. 1. ed. Rio de Janeiro: Ponteio, FAPERJ, 2014.

ELIAS, N. Sobre o tempo. Rio de Janeiro: Jorge Zahar, 1998.

ESCOLANO, A. Arquitetura como programa. espaço-escola e currículo. In: FRAGO, A. V.; ESCOLANO, A. Currículo, espaço e subjetividade: a arquitetura como programa. Rio de Janeiro: DP\&A, 1998.

FRAGO, A. V. Do espaço escolar e da escola como lugar: propostas e questôes. In: FRAGO, A. V.; ESCOLANO, A. Currículo, espaço e subjetividade: a arquitetura como programa. Rio de Janeiro: DP\&A, 1998.

GADOTTI, M. Educação integral no Brasil: inovaçóes em processo. São Paulo: Editora e Livraria Instituto Paulo Freire, 2009 (Educação Cidadã).

GOMÉZ-GRANELL, C.; VILA, I. Introdução. In: GOMÉS-GRANELL, C.; VILA, I. (Org.). A cidade com um projeto educativo. Porto Alegre: Atmed, 2003.

VINTRÓ, E. Educação, escola, cidade: o projeto educativo da cidade de Barcelona. In: GOMÉS-GRANELL, C.; VILA, I. (Org.). A cidade com um projeto educativo. Porto Alegre: Atmed, 2003.

SANTOS, M. A natureza do espaço. Técnica e tempo. Razão e emoção. São Paulo: Editora Hucitec, 1996.

SILVA, B. A. R. da. Interesses, dilemas e a implementação do Programa Mais Educação no município de Maricá (RJ). 275 p. 2013. Tese (Doutorado em Educação). - Universidade Federal do Rio de Janeiro (UFRJ), Rio de Janeiro, 2013.

PAIVA, F. R. S.; AZEVEDO, D. S. de; COELHO, L. M. C. C. Concepçóes de educação integral em propostas de ampliação do tempo escolar. Revista Instrumento: Revista de Estudo e Pesquisa em Educação. Juiz de Fora, v. 16, n. 1, jan./jun. 2014.

PARENTE, C. M. D. A construção dos tempos escolares. Educação em Revista. Belo Horizonte, v. 26, n. 02, p. 135156, ago. 2010. 
PARENTE, C. M. D. A construção dos tempos escolares: possibilidades e alternativas plurais. 173 p. 2006. Tese (Doutorado em Educação) - Faculdade de Educação, Universidade Estadual de Campinas, Campinas, 2006.

MOLL, J. (Org.). Educação Integral. Texto referência para o debate nacional. Brasília: MEC/SECADI, 2009 (Série Mais Educação).

Enviado em 10 de dezembro de 2016.

Aprovado em 03 de setembro de 2017. 